\title{
RESSIGNIFICANDO OS ESTÁGIOS OBRIGATÓRIOS DO CURSO DE LETRAS/EAD/UFMS: Os Desafios Impostos pela Pandemia, as Estratégias e as Possibilidades
}

\author{
Patrícia Rocha ${ }^{1}$ \\ Daniela Kawamoto Kanashiro ${ }^{2}$ \\ Ana Karla Pereira de Miranda ${ }^{3}$
}

\section{RESUMO}

A pandemia causada pela Covid-19 forçou-nos a repensarmos e a reorganizarmos várias ações universitárias, entre elas o prosseguimento dos Estágios Obrigatórios dos cursos de Licenciatura para que fosse possível atender à legislação vigente e às medidas emergenciais adotadas. Neste trabalho discutimos o desenvolvimento das atividades nos Estágios Obrigatórios do curso de Letras Português e Espanhol, na modalidade a distância, da UFMS, durante o período pandêmico com o objetivo de descrever e analisar a reorganização desse componente curricular durante o Ensino Remoto Emergencial (ERE), refletindo sobre a avaliação realizada pelos/as acadêmicos/as e sobre os possíveis impactos desse novo formato na formação desses/as professores/as. A partir da conjugação de métodos quantitativos e qualitativos de geração de dados, analisamos excertos de narrativas e respostas do questionário on-line a respeito dos efeitos das mudanças nesse componente curricular na formação de professores de Português e Espanhol. O aporte teórico pauta-se em Piconez (1994, 2004), Pimenta (2009), Santos, Cunha e Moraes (2020), entre outros, quanto ao estágio, e em Freire (1987), Hooks (2017) e Souza (2006), no que respeita à formação de professores. Como resultados destacamos a avaliação em sua maioria positiva pelos/as participantes da pesquisa em relação ao estágio, suas expectativas otimistas sobre o futuro profissional, bem como as dificuldades que impactaram a formação docente, sobretudo no que diz respeito à socialização profissional.

Palavras-chave: Formação inicial docente; licenciatura; ensino remoto emergencial.

REFRAMING THE PRACTICUM IN DISTANCE EDUCATION LANGUAGE AND LITERATURE COURSE FROM UFMS: THE CHALLENGES IMPOSED BY THE PANDEMIC, THE STRATEGIES AND THE POSSIBILITIES

\begin{abstract}
The pandemic caused by Covid-19 enforced us to rethink and reorganize several university actions, amongst them, the continuation of the Bachelor of Education Practicums so it was possible to comply with current legislation and emergency measures adopted. In this work, we discuss the development of the Practicum activities taken place in distance education Language and Literature course, with emphasis in Portuguese and Spanish, from UFMS, during the pandemic period in order to describe and analyze the reorganization of this curricular component during emergency remote teaching (ERT), reflecting on the appraisal carried out by the students and the possible impacts of this new format on the education of these teachers. From the combination of quantitative and qualitative data generation methods, we analyze excerpts from the narratives and the questionnaire answers regarding the effects of changes in this curricular component in Portuguese and Spanish teacher education. The theoretical framework is based on Piconez (1994, 2004), Pimenta (2009), Santos et al. (2020), between others, as for the Practicum, and on Freire (1987), Hooks (2017) and Souza (2006), concerning teacher education. As results, we highlight the mostly positive evaluation by research participants in relation to the Practicum, their optimist expectations about their professional future, as well as the difficulties that impacted teacher education, especially in regard to professional socialization.

Keywords: Teacher education; bachelor of education; emergency remote teaching.
\end{abstract}

RECEBIDO EM: 30/8/2021

ACEITO EM: 8/10/2021

\footnotetext{
1 Autora correspondente. Universidade Federal de Mato Grosso do Sul - Faculdade de Artes, Letras e Comunicação. Cidade Universitária, Av. Costa e Silva, Pioneiros. CEP 79070-900. Campo Grande/MS, Brasil. http://lattes.cnpq.br/2285085743040936. https://orcid.org/00000002-8814-9613. patrigraciro@gmail.com

2 Universidade Federal de Mato Grosso do Sul - Faculdade de Artes, Letras e Comunicação. Campo Grande/MS, Brasil. http://lattes.cnpq.br/ 8575589038783840. http://orcid.org/0000-0001-5017-1420

3 Universidade Federal de Mato Grosso do Sul - Faculdade de Artes, Letras e Comunicação. Campo Grande/MS, Brasil. http://lattes.cnpq.br/ 6016362239387981. http://orcid.org/0000-0002-2151-0021.
} 
O profissional do ensino não é um técnico, um especialista, é antes de mais nada um profissional do humano, do social, do político. Moacir Gadotti

\section{INTRODUÇÃO}

Este artigo é um recorte dos estudos vinculados ao projeto de pesquisa Formação inicial e continuada de professores na contemporaneidade, desenvolvido pelos membros do Grupo de Estudos e Pesquisas em Linguagens e Educação (Geple), da Universidade Federal de Mato Grosso do Sul (UFMS).

Neste trabalho discutimos o desenvolvimento das atividades nos Estágios Obrigatórios do curso de Letras Português e Espanhol, na modalidade a distância, da UFMS, durante o período pandêmico. Dessa forma, objetivamos descrever e analisar a reorganização desse componente curricular durante o Ensino Remoto Emergencial (ERE), refletindo sobre possíveis impactos na formação de professores. Justificamos o desenvolvimento da pesquisa, pois a pandemia causada pela Covid-19 forçou-nos a repensar e reorganizar as ações de estágio rapidamente, a fim de atender à legislação vigente e às medidas emergenciais, uma vez que as escolas de Educação Básica, local das atividades práticas, estavam com as portas fechadas em virtude da necessidade de isolamento físico.

Ainda que já estivéssemos acostumadas com as interações on-line, devido às características próprias da Educação a Distância (EaD), nosso lócus de atuação, muitas reuniões e discussões foram necessárias para que fosse possível pensar coletivamente em novos formatos, novas estratégias e novas metodologias para esse componente curricular extremamente relevante na/para a formação de professores.

Nas partes subsequentes do trabalho apresentamos a metodologia que conjugou métodos quantitativos e qualitativos na análise dos dados emitidos por 34 participantes que responderam questões objetivas e discursivas em questionário compartilhado via Google Forms. Também foram analisados excertos de narrativas acerca dos estágios realizados durante a pandemia, expressos nos seus relatórios finais das referidas disciplinas. Na sequência, discorremos sobre o arcabouço teórico que fundamenta nossas análises. Entre as referências, citamos, no âmbito dos estágios, os estudos de Piconez (1994, 2004), Pimenta (2009), Santos, Cunha e Moraes (2020), entre outros e, sobre formação de professores, nos ancoramos em Freire (1987), Hooks (2017) e Souza (2006). $\mathrm{Na}$ análise, focamos a avaliação majoritariamente positiva dos/as estagiários/as participantes da pesquisa, suas expectativas otimistas em relação a seu futuro profissional, bem como as dificuldades que impactaram, sobretudo, sua socialização profissional. Para concluir, expomos as considerações finais e as referências.

\section{O QUE A TEORIA DIZ SOBRE O ESTÁGIO?}

Antes de tratar especificamente do estágio, foco deste texto, precisamos manifestar nossa filiação teórica que nos impulsiona a defender uma educação como prática da liberdade (HOOKS, 2017; FREIRE, 1967) e, ao mesmo tempo, a combater a "educação bancária" (FREIRE, 1987) baseada na noção de que tudo o que os alunos precisam fazer 
é consumir a informação dada por um professor e ser capazes de memorizá-la e armazená-la. Assim, acreditamos na práxis que implica ação e reflexão "dos homens sobre o mundo para transformá-lo" (FREIRE, 1987, p. 46).

A partir dessa filiação vale mencionar que compreendemos a formação como uma iniciação e como um processo por que ela revela "conexões com as experiências que se constroem ao longo da vida, por meio das singularidades das histórias de vida e das trajetórias de escolarização" (PETERS apud SOUZA, 2006, p. 139). Esse entendimento nos move a pesquisar a nossa própria prática, no sentido de apreender as implicações sobre a formação inicial, o estágio como iniciação e as narrativas e avaliações dos estagiários como possibilidades de transformação das identidades e subjetividades. Tal posicionamento nos faz superar o conceito de formação como "transferência de conhecimento" ou "preparação para um ofício ou um fazer", ou ainda uma atividade essencialmente técnica e nos leva a ressignificá-la como um campo de ação e pesquisa concernente ao desenvolvimento pessoal e coletivo por meio das experiências do indivíduo e do grupo (HONORÉ apud SOUZA, 2006).

Dito isso, passamos a tratar especificamente das questões relacionadas aos estágios supervisionados nos cursos de Licenciatura. Para Pimenta (2009, p. 219), a finalidade do estágio é "[...] colaborar no processo de formação dos educadores, para que estes, ao compreender e analisar o espaço de sua atuação possam proceder a uma inserção profissional crítica, transformadora e criativa".

Para Santos, Cunha e Moraes (2020), o estágio supervisionado é uma etapa fundamental no processo de formação profissional, especialmente de professores, pois trata-se de um momento em que o estudante tem a chance de vivenciar, mesmo que parcialmente, a prática docente e, além disso, é nesse período que o estagiário tem a oportunidade de recontextualizar as lições e conteúdos vistos em sala de aula para a prática, analisando criticamente as possibilidades e enfrentando os desafios.

Libâneo (2010), referindo-se à formação de professores, destaca que a tendência investigativa mais recente e mais forte é a que concebe o ensino como atividade reflexiva. Esse conceito perpassa não apenas a formação como também o currículo, o ensino e a metodologia de docências.

Piconez (2004) defende que a proposta de estágio deve estar voltada para um atendimento à comunidade, proporcionando o engajamento do estagiário na realidade escolar na qual irá atuar, para que este possa perceber os desafios oferecidos pela carreira do magistério a fim de poder refletir sobre a profissão que vai assumir. Para a autora, esse envolvimento em situações reais vividas visará primordialmente à integração do saber com o fazer. Ela defende ainda que o estágio deve ser realizado essencialmente em escolas da rede pública de ensino, uma vez que é lá que o estagiário terá esse encontro com a realidade da comunidade com a qual irá trabalhar.

Partilhando do mesmo posicionamento de Piconez (2004) e considerando o cenário da Educação Básica brasileira causado pela crise sanitária de Covid-19 - o ERE - avaliamos que era mais adequado para esse momento histórico-social que o estágio obrigatório do nosso curso fosse pensado e organizado para essa realidade escolar específica e atípica de isolamento social que estávamos vivenciando, ou seja, sem aulas presen- 
ciais. Assim, acreditamos que não fazia sentido, no início de 2020, continuar apostando em um modelo de estágio construído para um contexto de "normalidade", nem esperar a pandemia passar para que o estágio pudesse ser realizado.

No que se refere à relação teoria e prática, tradicionalmente mencionada na conceituação de estágios supervisionados, Pimenta (2009) defende que o papel da teoria é oferecer aos professores perspectivas de análise para compreender os contextos históricos, sociais, culturais e de si mesmos como profissionais, nos quais se dá sua atividade docente, para neles intervir, transformando-os. Segundo Esteban e Zaccur (2002), a prática é o ponto de partida, pois dela emergem as questões, as necessidades e as possibilidades, isto é, ela esboça os caminhos a serem percorridos. Para Pimenta (2009), entretanto, o estágio curricular não é uma atividade prática, mas teórica, uma vez que é instrumentalizadora e transformadora da prática docente.

Libâneo (2010) destaca a necessidade de reflexão sobre a prática para apropriação e produção de teorias, como marco para a melhoria das práticas de ensino. $O$ autor defende uma formação docente que seja crítico-reflexiva, na qual o professor é ajudado a compreender o seu próprio pensamento e a refletir criticamente sobre sua própria prática. Para Piconez (1994), a teoria surge a partir da prática, é elaborada em razão desta e sua verdade é verificada pela própria prática.

De acordo com Esteban e Zaccur (2002), a prática transforma-se em práxis quando acontece essa relação dialógica em que ocorre um processo reflexivo na busca por novos conhecimentos. Para a autora, a prática é ao mesmo tempo objeto de conflitos e terreno no qual estes se desenvolvem, então o papel da teoria seria o da mediação.

Na concepção de Perrenoud (2002), a formação de bons professores tem a ver, principalmente, com a formação de pessoas capazes de evoluir, de aprender de acordo com a experiência, refletindo sobre o que gostaria de fazer, sobre o que realmente fizeram e sobre o resultado de tudo isso.

Pimenta (2009) defende um estágio voltado para o desenvolvimento de atividades que possibilitem o conhecimento, a análise e a reflexão das ações docentes, a fim de compreendê-las em seu contexto histórico, identificando suas dificuldades e os resultados que se apresentam. Para a autora, o estágio deixa de ser considerado um apêndice do currículo e passa a integrar o corpo de conhecimento do curso.

Assim, nos alinhamos a Esteban e Zaccur (2002), Libâneo (2010) e Pimenta (2009), entre outros, que defendem um estágio voltado para práticas significativas, que façam com que o aluno seja capaz de, a partir de uma análise crítica baseada nos conhecimentos teóricos, apontar para possíveis transformações nas práticas escolares, contribuindo, dessa forma, para a educação em nosso país.

Ao entendermos a formação e o estágio como práticas de iniciação, passamos a vê-los como um processo vinculado a uma prática institucionalizada e formativa, marcada pelas experiências e aprendizagens construídas ao longo da vida, implicando o desenvolvimento pessoal, a preparação para a realização profissional de uma prática educativa contextualizada, reflexiva, crítica e transformadora (SOUZA, 2006). 
Entender o estágio e o lugar que têm as experiências no processo de formação e na transformação das identidades e subjetividades, a partir da centralidade na pessoa do professor, envolve ordens diversas de complexidade, de múltiplos problemas teórico-práticos relacionados a aprendizagens da docência, aos repertórios de conhecimentos necessários ao desenvolvimento profissional e, consequentemente, à superação de que a instrumentalização técnica e didático-pedagógica garante, por si só, tanto o tempo da formação inicial quanto o exercício desenvolvido no estágio, como o período institucionalizado e formal, sistematicamente organizado para o exercício da profissão (SOUZA, 2006, p. 141).

Ao superarmos a compreensão do estágio como um momento de confronto entre teoria e prática, ou como um praticismo voltado ao treino ou à experimentação de atividades de ensino, defendemos outra perspectiva sobre o processo de formação que assume o estágio como uma prática de iniciação ao trabalho pedagógico.

Assim, os futuros professores também devem ser instigados a se questionar, no momento do estágio, com relação à estruturação dos espaços escolares, sua organização e planejamento, contemplando o plano educacional, o plano de ensino e o plano de aula. "Esses três planos compõem a tríade que sustenta a proposição de ações pedagógicas" (SILVA; SILVA, 2020, p. 315) e envolvem a atuação efetiva do professor, constituindo a documentação que orienta o trabalho docente, a pesquisa e a reflexão, momento em que o professor se volta de maneira consciente para avaliar os efeitos intelectuais, físicos, emocionais, sociais e culturais da sua intervenção.

\section{ALTERAÇÕES NOS ESTÁGIOS DE LETRAS EAD/UFMS DURANTE A PANDEMIA}

No atual momento pandêmico, em que enfrentamos uma crise sem precedentes que combina fatores sanitários e econômicos, não podemos perder de vista o direito à educação, mesmo em contextos de ameaça à vida. Esse contexto, entre os inúmeros impactos decorrentes da suspensão de aulas e de atividades presenciais, convocou-nos a observar e a pensar alternativas para a validação do componente Estágio Supervisionado no curso de Licenciatura em que estamos inseridas, à luz de estratégias que considerassem as atividades formativas do ensino remoto, tanto aquelas já integrantes do currículo do curso ou propostas a partir da necessidade de replanejamento advinda da pandemia.

Assim sendo, dispusemo-nos a repensar o formato do Estágio Supervisionado do nosso curso de uma maneira que pudéssemos dar continuidade ao calendário acadêmico sem que houvesse um prejuízo no tempo destinado à integralização do curso.

Nesse novo cenário, foi necessária a elaboração e aprovação de um Regulamento Emergencial de Estágio do Curso que atendesse à Portaria $n^{\circ} 405$, de 16 de março de 2020, por meio da qual o reitor da Fundação Universidade Federal de Mato Grosso do Sul, considerando a Instrução Normativa $n^{\circ} 1$, de 31 de agosto de 2018, e a Instrução Normativa $n^{\circ} 19$, de 12 de março de 2020, da Secretaria de Gestão e Desempenho de Pessoal do Ministério da Economia, as deliberações do Comitê Operativo de Emergência (COE/UFMS), criado pela Portaria $n^{\circ} 387$, de 12 de março de 2020, a Portaria $n^{\circ} 394$, de 13 de março de 2020, instituiu medidas temporárias, novos procedimentos e outras 
providências a serem adotadas, no âmbito da UFMS, com a ressalva da excepcionalidade da situação para a prevenção do contágio e o enfrentamento da emergência de saúde pública de importância internacional decorrente da pandemia causada pelo novo coronavírus, no período de 17 de março a 17 de abril de 2020.

Depois disso, a referida Portaria foi sendo atualizada até que fosse criada a Resolução $n^{\circ} 228$, de 13 de agosto de 2020, que regulamentou o Ensino Remoto de Emergência (ERE) para os cursos de Graduação, presenciais e a distância, no âmbito da UFMS, enquanto durar a situação da Covid-19. Tal resolução considerava o estabelecido na Portaria no 544/MEC, de 16 de junho de 2020, e no Parecer CNE/CP no 11, aprovado em 7 de julho de 2020. Enquanto isso, as aulas não pararam na UFMS, houve apenas duas semanas de recesso para que os cursos se reorganizassem e se adaptassem ao novo formato.

Considerando que o Estágio Supervisionado é um componente essencial de profissionalização docente dos cursos de Licenciatura e que ele deve estar intimamente atrelado às características e às mudanças na sociedade, acreditamos que os campos de estágio do professor em formação inicial são os espaços da Educação Básica, como se referencia nos documentos legais e, em especial, a sala de aula, para o exercício da regência, prática de ensino, docência. Privar-se desse espaço, por imposição de medidas sanitárias e de preservação da vida, exigiu uma tomada de decisão que contemplasse as possibilidades de sua realização na condição de ensino remoto, não presencial. Essa tarefa não foi nada fácil, mas era urgente e, ao mesmo tempo, necessária. Tudo mudou repentinamente: a sociedade, a escola, o ensino... então, não poderíamos insistir em um estágio que não fosse pensado para esse contexto real, por pior que ele parecesse.

O espaço público de nossas vidas e, em especial, das escolas, foi retirado de nosso cotidiano. Como profissionais e estudantes, a vida nas instituições de ensino teve de se reconfigurar perante uma tela de computador ou outro equipamento semelhante. Como professores e estudantes, fomos forçados a remodelar as práticas para a continuidade da oferta escolar por meio do ensino remoto. As universidades enfrentaram os problemas decorrentes da desigualdade de acesso e de condições para a inclusão digital, a ausência de formação para o domínio das diferentes práticas digitais, além de aspectos estruturais e de gestão do conhecimento (SOUZA; FERREIRA, 2020).

Com efeito, a suspensão das atividades letivas presenciais, por todo o mundo, gerou a obrigatoriedade dos professores e estudantes migrarem para a realidade on-line, transferindo e transpondo metodologias e práticas pedagógicas típicas dos territórios físicos de aprendizagem, naquilo que tem sido designado por ensino remoto de emergência. E na realidade, essa foi uma fase importante de transição em que os professores se transformaram em youtubers, gravando videoaulas e aprenderam a utilizar sistemas de videoconferência, como o Skype, o Google Hangout ou o Zoom e plataformas de aprendizagem, como o Moodle, o Microsoft Teams ou o Google Classroom. No entanto, na maioria dos casos, estas tecnologias foram e estão sendo utilizadas numa perspectiva meramente instrumental, reduzindo as metodologias e as práticas a um ensino apenas transmissivo. É, pois, urgente e necessário transitar deste ensino remoto de emergência, importante numa primeira fase, para uma educação digital em rede de qualidade (MOREIRA; HENRIQUES; BARROS, 2020 apud SOUZA; FERREIRA, 2020, p. 11). 
Nesse contexto, pusemos-nos a considerar a possibilidade de ofertar o Estágio Supervisionado do curso de Licenciatura em Letras Português e Espanhol da modalidade a distância da UFMS por meio do ensino remoto, desde que se mantivesse preservada a seguinte arquitetura curricular:

Quadro 1 - Atividades expressas no plano de atividades do estagiário

\begin{tabular}{|l|c|}
\hline Atividades a serem resolvidas & Carga horária \\
\hline Orientações síncronas e assíncronas. & $12 \mathrm{~h}$ \\
\hline $\begin{array}{l}\text { Etapa de observação de aulas (substituída por atividades remotas, conforme a Resolu- } \\
\text { ção no 20, de } 4 \text { de junho de 2020, do curso de Letras Português e Espanhol/EAD) }\end{array}$ & $10 \mathrm{~h}$ \\
\hline $\begin{array}{l}\text { Etapa de coparticipação (substituída por atividades remotas, conforme a Resolução no } \\
\text { 20, de } 4 \text { de junho de 2020, do Curso de Letras Português e Espanhol/EAD) }\end{array}$ & $20 \mathrm{~h}$ \\
\hline Elaboração e postagem dos planos de aula. & $20 \mathrm{~h}$ \\
\hline Apresentação síncrona dos planos de aula. & $20 \mathrm{~h}$ \\
\hline Elaboração de relatório final. & $20 \mathrm{~h}$ \\
\hline CARGA HORÁRIA TOTAL & $102 \mathrm{~h}$ \\
\hline
\end{tabular}

Fonte: COE do curso de Letras EaD/UFMS.

Compreendemos que, se preservada a estrutura prevista no Quadro 1 para a materialização do estágio, na sua compreensão de atividade supervisionada e monitorada por docente da Educação Superior, seria possível ao estudante a vivência no tempo/ espaço virtual da aula remota.

Depois de passado um ano desse novo formato de estágio (que durou um ano e meio e que permanece até o momento do fechamento deste texto, agosto de 2021), entretanto, era preciso avaliar o efeito dele nos acadêmicos em formação e, além disso, era necessário que eles refletissem criticamente sobre a sua própria trajetória e avaliassem todo o processo. Isso nos levou a realizar esta pesquisa e a analisar seus resultados sob a luz do aporte teórico mencionado.

\section{METODOLOGIA}

Para este estudo desenvolvemos uma pesquisa de natureza aplicada, associando métodos quantitativo e qualitativo, estudo bibliográfico e análise de dados resultantes da aplicação de questionário on-line e de narrativas dos estagiários. No caso do questionário, foram compartilhadas, via Google Forms, 15 questões objetivas e duas discursivas. A participação não foi obrigatória e os/as estudantes não precisavam identificar-se.

Dos 39 graduandos/as matriculados/as no último semestre do curso de Letras Português e Espanhol EaD/UFMS (20, no polo de Bela Vista e 19 no polo de Bonito), 34 participaram desta pesquisa. 
É importante mencionar que se trata da sexta oferta do curso com financiamento da Universidade Aberta do Brasil (UAB). De 2008 até 2021, houve mais de 290 concluintes do curso de Letras, egressos de vários polos localizados em diferentes municípios do Estado de Mato Grosso do Sul, quais sejam, Água Clara, Bataguasssu, Bela Vista, Bonito, Camapuã, Costa Rica, Miranda, Porto Murtinho, Rio Brilhante e São Gabriel do Oeste. A partir de 2017 não houve mais abertura de novas turmas de cursos de Graduação EaD, na UFMS e, conforme mencionamos, no primeiro semestre de 2021, concluíram as duas últimas turmas, em Bela Vista e Bonito.

Com relação ao perfil dos/as formandos/as que participaram da investigação, temos $44,1 \%$ entre 31 e 40 anos; $29,4 \%$ com mais de 41 anos e apenas $26,5 \%$ têm entre 21 e 30 anos. Esse dado comprova que o objetivo da $U A B$, de interiorização do Ensino Superior público, atinge uma parcela significativa de pessoas que não tiveram oportunidade de cursar uma Graduação logo após a conclusão da Educação Básica.

Entre os/as participantes, $67,6 \%$ identificam-se como mulher, $29,4 \%$ como homem e $3 \%$ preferiram não dizer. A grande maioria dos cursos de Licenciatura ainda é formada pelo público feminino (GATTI, 2010).

Vale ressaltar que embora os/as estudantes estivessem matriculados/as nos dois referidos polos, vários deles moram em municípios vizinhos, o que amplia ainda mais o alcance da interiorização do Ensino Superior público. Entre os/as participantes, 52,9\% residem em Bela Vista; 38,2\% em Bonito e os demais em Bodoquena, Campo Grande e Nioaque.

Para $50 \%$ dos/as respondentes, o curso de Letras é a realização da primeira Graduação; 26,5\% têm outra formação não relacionada à área da educação e 23,5\% já possuíam outra Licenciatura. Além disso, 55,9\% nunca tiveram experiência docente em sala de aula presencial; $23,5 \%$ responderam que já possuíam experiência como substituto/a; $14,7 \%$ como contratado/a e 5,9\% como concursado/a. Esses dados revelam que para cerca de metade dos/as participantes os estágios obrigatórios representam a primeira experiência em sala de aula como docentes de Espanhol e de Português e Literatura.

\section{APRESENTAÇÃO E ANÁLISE DOS DADOS}

O momento de geração de dados compreendeu o primeiro semestre de 2021. Nesse período, os/as licenciandos/as cursavam o último semestre e, entre outras disciplinas, os Estágios Obrigatórios em Língua Espanhola e em Língua Portuguesa e Literatura, ambos no Ensino Médio, cada uma com 102h. Anteriormente, em 2020, haviam cursado, também de forma remota, os Estágios Obrigatórios em Espanhol e em Língua Portuguesa e Literatura referentes ao Ensino Fundamental, igualmente com $102 \mathrm{~h}$ cada uma. O curso totaliza, portanto, $408 \mathrm{~h}$ de estágios.

Segundo o Projeto Pedagógico do Curso (PPC) (FUNDAÇÃO..., 2019), os quatro estágios estão distribuídos em semestres diferentes, sendo o de Espanhol no Ensino Fundamental e no Ensino Médio, no quinto e no sétimo anos, respectivamente, e o de Língua Portuguesa e Literatura no Ensino Fundamental e no Ensino Médio, no sexto e oitavo, também nessa ordem. Devido aos ajustes decorrentes do isolamento físico, houve alterações na oferta dessas disciplinas no que respeita à sua semestralização. 
No quadro a seguir descrevemos as atividades de estágios, desenvolvidas no primeiro semestre de 2021, de acordo com a aprovação: (i) dos planos de ensino pelo colegiado do curso e (ii) dos planos de atividades do estagiário pela Comissão de Estágio (COE).

Quadro 2 - Atividades desenvolvidas nos Estágios Obrigatórios, no primeiro semestre de 2021

\begin{tabular}{|c|c|c|}
\hline 2021.1 & Polo de Bela Vista & Polo de Bonito \\
\hline $\begin{array}{l}\text { Estágio } \\
\text { Obrigatório } \\
\text { em Língua } \\
\text { Portuguesa e } \\
\text { Literatura no } \\
\text { Ensino Médio }\end{array}$ & $\begin{array}{l}\text { - elaboração de um diário de escola - tra- } \\
\text { jetória completa como aluno antes e pós } \\
\text { EaD/UFMS, a partir da leitura reflexiva do } \\
\text { livro "Diário de escola" de Daniel Penac. } \\
\text { - produção de um texto narrativo contan- } \\
\text { do acerca da experiência do ano de } 2020 \\
\text { e } 10 \text { o semestre de } 2021 \text { sobre o ensino } \\
\text { fora do espaço tradicional da sala de aula, } \\
\text { a partir do filme "Além da sala de aula"; } \\
\text { - análise dos livros didáticos de Língua } \\
\text { Portuguesa e Literatura de Ensino Médio } \\
\text { utilizados nas escolas da cidade onde } \\
\text { reside; } \\
\text { - elaboração de duas sequências didá- } \\
\text { ticas [uma de LP e outro de L] para o } \\
\text { ensino remoto, a partir da análise do livro } \\
\text { didático; } \\
\text { - apresentação desses planos de aula ao } \\
\text { vivo, via Google Meet; } \\
\text { - elaboração de relatório final; } \\
\text { - produção e publicação de um livro com } \\
\text { a coletânea de todos os diários de escola } \\
\text { produzidos pelas duas turmas. A partici- } \\
\text { pação no livro era optativa. OBS: o livro } \\
\text { está no prelo e será publicado pela edito- } \\
\text { ra Pimenta Cultural em } 2021.2 \text {. }\end{array}$ & $\begin{array}{l}\text { - elaboração de um diário de escola - } \\
\text { trajetória completa como aluno antes e } \\
\text { pós EaD/UFMS, a partir da leitura refle- } \\
\text { xiva do livro "Diário de escola" de Daniel } \\
\text { Penac. } \\
\text { - produção de um texto narrativo con- } \\
\text { tando acerca da experiência do ano de } \\
2020 \text { e } 10 \text { o semestre de } 2021 \text { sobre o } \\
\text { ensino fora do espaço tradicional da sala } \\
\text { de aula, a partir do filme "Além da sala } \\
\text { de aula"; } \\
\text { - análise dos livros didáticos de Língua } \\
\text { Portuguesa e Literatura de Ensino Médio } \\
\text { utilizados nas escolas da cidade onde } \\
\text { reside; } \\
\text { - elaboração de duas sequências didáti- } \\
\text { cas [uma de LP e outro de L] para o en- } \\
\text { sino remoto, a partir da análise do livro } \\
\text { didático; } \\
\text { - apresentação desses planos de aula ao } \\
\text { vivo, via Google Meet; } \\
\text { - elaboração de relatório final; } \\
\text { - produção e publicação de um livro com } \\
\text { a coletânea de todos os diários de escola } \\
\text { produzidos pelas duas turmas. A partici- } \\
\text { pação no livro era optativa. OBS: o livro } \\
\text { está no prelo e será publicado pela edito- } \\
\text { ra Pimenta Cultural em } 2021.2 \text {. }\end{array}$ \\
\hline $\begin{array}{l}\text { Estágio } \\
\text { Obrigatório } \\
\text { em Língua } \\
\text { Espanhola no } \\
\text { Ensino Médio }\end{array}$ & $\begin{array}{l}\text { - observação do contexto pandêmico no } \\
\text { âmbito familiar e escolar, considerando } \\
\text { vivências e notícias veiculadas em mídias; } \\
\text { - orientações sobre o gênero discursivo } \\
\text { videoaula; } \\
\text { - elaboração de planos de aula e de ma- } \\
\text { teriais didáticos; } \\
\text { - simulação da gravação da videoaula; } \\
\text { - orientações sobre o uso do Zoom para } \\
\text { gravação dos vídeos; } \\
\text { - gravação e compartilhamento de uma } \\
\text { videoaula; } \\
\text { - elaboração de relatório final. }\end{array}$ & $\begin{array}{l}\text { - reflexão sobre os gêneros discursivos } \\
\text { digitais e as perspectivas do ensino pós- } \\
\text {-pandemia, com base em artigos acadê- } \\
\text { micos; } \\
\text { - elaboração de plano de aula e de mate- } \\
\text { rial didático sobre um gênero discursivo } \\
\text { digital; } \\
\text { - apresentação do material didático, } \\
\text { conforme o plano de aula elaborado, e } \\
\text { discussões em torno das dificuldades e } \\
\text { possíveis aplicações no ensino pós-pan- } \\
\text { dêmico. }\end{array}$ \\
\hline
\end{tabular}

Fonte: Elaboração própria. 
Por meio das atividades explicitadas no Quadro 2, buscamos adaptar o estágio de modo que ele permanecesse sendo um campo de formação, isto é, de pesquisa e ação (SOUZA, 2006). Procuramos, por meio dessas propostas, que os/as futuros/as professores/as pudessem recontextualizar os conteúdos estudados durante o curso e analisar, criticamente, as possibilidades e desafios que hão de enfrentar em sua prática pedagógica (SANTOS; CUNHA; MORAES, 2020), de modo a transformar a prática em práxis (ESTEBAN; ZACCUR, 2002), mesmo que de maneira adaptada, dado o contexto sanitário vivenciado.

A partir do questionário avaliativo que submetemos aos/às acadêmicos/as no primeiro semestre de 2021 , foi possível verificar que $85,3 \%$ deles consideraram o estágio muito relevante e $14,7 \%$ assinalaram como relevante essa etapa para a sua formação como professor. Quanto a isso, ressaltamos que embora, entre as respostas, figurasse a opção irrelevante, nenhum participante a escolheu.

Ao solicitarmos que eles/elas avaliassem a forma como os estágios obrigatórios foram conduzidos no período da pandemia, vimos que $47 \%$ avaliaram como ótima, $35,3 \%$ como bom, $11,8 \%$ como regular, $2,9 \%$ ruim e 2,9\% péssima.

Ao questionarmos se eles/elas achavam que os estágios obrigatórios poderiam ser conduzidos de outra maneira, constatamos que $70,6 \%$ consideraram que não, $26 \%$ responderam que talvez e $2,9 \%$ que sim. Na sequência dessa pergunta, pedimos a eles/ elas que dissertassem sobre como seria essa outra forma, caso houvessem respondido que sim, e obtivemos a seguinte resposta:

Propor aulas on-line com estudantes, assim como é feito com os professores regentes, em alguns momentos do ano letivo (Estagiário/a1).

A esse respeito, destacamos que considerando as dificuldades enfrentadas para a inserção dos estagiários nos espaços virtuais das escolas, bem como o fato de, em muitas dessas instituições, o ensino remoto ser efetuado por meio de atividades impressas, o curso optou pelo desenvolvimento das atividades teórico-práticas já mencionadas nas disciplinas de estágio. Dessa forma, o contexto pandêmico impossibilitou um contato direto do/a professor/a em formação com o ambiente escolar, mesmo que virtualmente.

Os/as participantes também foram questionados/as se acreditavam que a ausência de contato presencial com os/as alunos/as da Educação Básica iria prejudicar sua preparação para atuar em sala de aula. Em suas respostas, $50 \%$ consideraram que não, $32,4 \%$ que talvez e $17,6 \%$ que sim.

Observamos que a ausência de contato com os/as estudantes da Educação Básica aparece como uma das inquietações dos/as estagiários/as mais uma vez. A adaptação do estágio à realidade imposta pela Covid-19 implicou a falta de socialização dos/as futuros/as docentes com o seu campo de atuação e com os sujeitos que dele participam. Nesse sentido, conforme supramencionado, Piconez (2004) destaca a necessidade de que o estágio esteja voltado ao atendimento da comunidade. Se por um lado, contudo, acreditamos que é na socialização desenvolvida no estágio que o/a professor/a em formação produz a aprendizagem de saberes a respeito da profissão, por outro lado, ainda que não tenham ocorrido da maneira ideal, os estágios, pela avaliação dos/as participantes, possibilitaram o conhecimento, a análise e a reflexão sobre a docência inserida 
em seu contexto histórico, evidenciando as dificuldades enfrentadas na sociedade atual (PIMENTA, 2009). Se a Educação Básica estava sendo conduzida de forma remota, nada mais adequado que os estágios também fossem pensados para esse tipo de formato.

A questão da atuação presencial em sala de aula aparece também quando os/ as questionamos a respeito do que achavam que havia faltado ou que poderia ter sido melhor, no curso de Letras. Entre as respostas obtidas, duas mencionaram o estágio especificamente, a saber:

Infelizmente a questão da prática nos estágios, mas isso são outros motivos e não do curso, que foi e está sendo ótimo(Estagiário/a 2).

Estou satisfeita com o curso, fui surpreendida positivamente, faltou o estágio em presencial, porém com o momento que estamos passando, tivemos que nos adaptar (Estagiário/a 3).

Observamos que o/a estudante percebe a impossibilidade da presencialidade no estágio como falta de prática, muito embora o estágio seja uma atividade teórico-prática, considerando os autores já mencionados (PICONEZ, 1994; PIMENTA, 2009). Compreendemos, desse modo, que a necessidade de adaptar a maneira de realizar essa prática, bem como a ausência de contato direto com a escola, promoveram uma lacuna na formação docente, na perspectiva de alguns participantes.

Quando questionados/as se se sentiam preparados para atuar como professores/ as na educação básica, $64,7 \%$ responderam que sim, 32,4\% que mais ou menos e $2,9 \%$ que não. Sabemos que mesmo que os estágios tivessem sido realizados de maneira presencial, considerando as nossas experiências como orientadoras dessa disciplina, muito provavelmente não alcançaríamos $100 \%$ de respostas positivas. A adaptação desse momento formativo ao contexto pandêmico, no entanto, impossibilitou a inserção profissional do futuro professor no ambiente escolar da maneira como se espera do estágio. Assim, acreditamos que esse contexto possa ter influenciado as respostas obtidas, embora, em sua maioria, suas expectativas sejam otimistas em relação a seu futuro profissional.

Destacamos, a seguir, algumas narrativas expressas nos relatórios de estágio, nas quais podemos observar reflexões dos estudantes sobre essa etapa de sua formação:

Hoje, no último semestre de Letras, estudando praticamente sozinho, admito que o curso me proporcionou uma visão crítica da minha trajetória escolar, mas, por conta da pandemia que assola o planeta, não pôde oportunizar o estágio nas escolas de ensino fundamental e médio, motivo pelo qual não posso tecer comentários a respeito dos alunos da rede estadual, onde ocorreria o estágio supervisionado (Diário do/a estagiário/a 4).

Ao final do nosso curso estamos passando pela pandemia, um cenário novo e cheio de surpresas. Reinventamo-nos de várias formas, e uma delas foi no que diz respeito à realização do estágio: fiquei apreensiva no começo, mas no final deu tudo certo. Estando agora na reta final, desejo que tudo aconteça da melhor maneira possivel (Diário do/a estagiário/a 5). 
A pandemia causada pelo novo coronavírus tem sido mais uma prova enfrentada, pois me foi imposto o desafio de buscar estratégias para encarar o isolamento social e aprender com as novas tecnologias e ferramentas virtuais disponíveis. Essa emergência sanitária exigiu de mim segurança para expor meus novos conhecimentos, compartilhá-los de modo virtual (alunos, colegas de turma), sem a presença física de outras pessoas, e, acima de tudo, entender que há um novo normal que se coloca pela frente, com novas perspectivas e outros desafios.

As conquistas das minhas lutas fortalecem meus projetos e sonhos: aplicar as tecnologias modernas aprendidas nos recantos rurais onde eu adentro, possibilitando aos meus colegas de trabalho e aos estudantes o acesso à informação com qualidade e às ferramentas do mundo moderno (Diário do/a estagiário/a 6).

No primeiro excerto evidencia-se a ausência de contato com os/as estudantes dos Ensinos Fundamental e Médio nas escolas públicas nas quais o estágio é comumente desenvolvido no curso em questão. Já o segundo trecho aponta a apreensão relativa a esse momento e o fato de as atividades terem sido realizadas conforme o planejado. Quanto ao terceiro fragmento, aborda uma das aprendizagens possibilitadas pelo estágio desenvolvido por meio do ERE: o uso de tecnologias digitais para o ensino e a aprendizagem. Embora os/as futuros/as docentes sejam estudantes de um curso da modalidade EaD, durante os estágios são poucas as oportunidades em que podem efetuar atividades em contexto virtual com os/as alunos/as. Dessa forma, a realização dessa etapa da formação de maneira on-line em sua totalidade possibilitou-lhes o desenvolvimento dessa habilidade.

\section{CONSIDERAÇÕES FINAIS}

Entre os resultados, destacamos a avaliação majoritariamente positiva dos/as participantes acerca do formato de estágio adotado no período pandêmico e as expectativas otimistas deles/as em relação ao futuro profissional.

Nos estágios realizados foi possível elaborar os documentos (planos de aula, relatórios, diários, etc.) e materiais didáticos por meio dos quais esse componente se efetiva, bem como desenvolvê-los mediante a realização de simulações de aulas e/ou videoaulas. Embora o contato com a realidade escolar não tenha se consolidado de maneira direta, foram desenvolvidas aprendizagens sobre a docência, tais como a transposição didática dos conteúdos, o uso das tecnologias digitais na educação, a reflexão crítica sobre o contexto educacional, entre outros.

É preciso destacar, todavia, que ainda que tenha havido esforços no sentido de proporcionar aos/às futuros/as docentes uma formação consistente e condizente com a realidade vivenciada, as dificuldades impostas pelo distanciamento físico impossibilitaram um aspecto importante da prática pedagógica e da construção da identidade dos/ as professores/as: a socialização com seu campo de atuação profissional.

\section{REFERÊNCIAS}

ESTEBAN, Maria Tereza; ZACCUR, Edwiges. A pesquisa como eixo da formação docente. In: ESTEBAN, Maria Tereza; ZACCUR, Edwiges (org.). Professora-pesquisadora: uma práxis em construção. Rio de Janeiro: DP\&A, 2002. p. 11-23.

FREIRE, Paulo. Educação como prática de liberdade. Rio de Janeiro: Editora Paz e Terra, 1967. 
FREIRE, Paulo. Pedagogia do oprimido. 17. ed. Rio de Janeiro: Paz e Terra, 1987.

FUNDAÇÃO UNIVERSIDADE FEDERAL DE MATO GROSSO DO SUL. Portaria no 405, 16 de março de 2020. Disponível em: https://docs.google.com/viewerng/viewer?url=https://www.ufms.br/wpcontent/ uploads/2020/03/SEI_UFMS-1855198-Portaria-405-RTR-16-03-2020-COVID19.pdf\&hl=pt_BR. Acesso em: 15 maio 2021a.

FUNDAÇÃO UNIVERSIDADE FEDERAL DE MATO GROSSO DO SUL. Resolução no 228, 13 de agosto de 2020. Disponível em: https://boletimoficial.ufms.br/bse/publicacao?id=401550. Acesso em: 11 maio $2021 \mathrm{~b}$.

FUNDAÇÃO UNIVERSIDADE FEDERAL DE MATO GROSSO DO SUL. Resolução no 532, 29 de outubro de 2018. Disponível em: https://boletimoficial.ufms.br/bse/publicacao?id=336825. Acesso em: 30 ago. 2021c.

GATTI, Bernardete A. Formação de professores no Brasil: características e problemas. Educ. Soc., Campinas, v. 31, n. 113, p. 1.355-1.379, out./dez. 2010. Disponível em: https://www.scielo.br/pdf/es/ v31n113/16. Acesso em: 1의. 2021.

HOOKS, Bell. Ensinando a transgredir: a educação como prática de liberdade. São Paulo: Editora Martins Fontes, 2017.

LIBÂNEO, José Carlos. Adeus professor, adeus professora? Novas exigências educacionais e profissão docente. São Paulo: Cortez, 2010.

PERRENOUD, Philippe. A prática reflexiva no ofício do professor: profissionalização e razão pedagógica. Porto Alegre: Artmed, 2002.

PICONEZ, Stela C. Bertholo (coord.). A prática de ensino e o estágio supervisionado. Campinas, SP: Papirus, 1994.

PICONEZ, Stela C. Bertholo. O Professor como pesquisador de sua prática pedagógica: a prática de Ensino na modalidade de Estágios Curriculares contribuindo com a construção da identidade profissional. Portal do Núcleo de Estudos em Eja e Formação de Professores, 2004.

PIMENTA, Selma Garrido; LIMA, Maria do Socorro Lucena. Estágio e docência. São Paulo: Cortez, 2009.

PIMENTA, Selma Garrido. O estágio na formação de professores: unidade teoria e prática? São Paulo: Cortez, 2010.

SANTOS, Rafael Ribeiro dos; CUNHA, Wânia Chagas Farias; MORAES, Loçandra Borges de. De aluno a professor - a realização de sonhos, um encontro com a realidade: o estágio supervisionado e sua relevância na formação docente. Revista Contexto \& Educação, v. 35, n. 112, p. 330-345, 2020. Doi: https://doi. org/10.21527/2179-1309.2020.112.330-345

SILVA, Camila Rubira; SILVA, Mauren Porciúncula da. Formação de docentes: uma análise de planos de aula divulgados na revista nova escola. Revista Contexto \& Educação, v. 35, n. 112, p. 314-329, 2020. DOI: https://doi.org/10.21527/2179-1309.2020.112.314-329

SOUZA, Elizeu Clementino. O conhecimento de si. Estágio e narrativas de formação de professores. Rio de Janeiro: DP\&A; Salvador, BA: Uneb, 2006.

SOUZA, Ester Maria de Figueiredo; FERREIRA, Lúcia Gracia. Ensino remoto emergencial e o estágio supervisionado nos cursos de licenciatura no cenário da pandemia Covid 19. Revista Tempos e Espaços em Educação, v. 13, n. 32, jan./dez. 2020. 